\title{
Modelling of Reactive Distillation for Acetic Acid Esterification
}

\author{
K.K.C.W. Kandanapitiya and M. Y. Gunasekera
}

\begin{abstract}
Esterification reactions are limited by chemical equilibrium and therefore they are carried out commercially using either a large excess of one of the reactants or by removing one of the products continuously. The removal of one of the products continuously can be achieved by carrying out reactive distillation where reaction and separation are performed simultaneously. This work presents an approach for mathematical modelling and simulation of batch reactive distillation which can be used by design engineers to obtain key information such as composition and temperature variation as the reaction progresses with time, product composition and the quantity accumulated in the distillate and the most suitable reflux conditions needed for high product separation rates. The process unit studied consists of a batch reactor with single stage distillation and a condenser. The mathematical model considered material balance equations, equilibrium relationships, summation equations and energy balance equations. The model was simulated for acetic acid and ethanol esterification reaction. The reactor composition variation in modelling and simulation results show a decrease in acetic acid and ethanol reactant compositions with time while ethyl acetate and water compositions show an increase. The ethyl acetate mole fraction in the condenser increases as the reflux ratio increases.
\end{abstract}

Keywords: Reactive distillation, modelling, esterification, ethyl acetate, reflux ratio

\section{Introduction}

Reactive distillation is one of the process intensification methods that combine the reactor and distillation process into one unit. The introduction of reaction kinetics into mass transfer zone leads to complex dynamics. The modelling of reactive distillation is essential for understanding the complex behaviour of reactive distillation.

There are many documented success stories involving the industrial implementation of reactive distillation $[1,2,3,4]$. The applications of reactive distillation in the chemical and petroleum industries have increased rapidly in the past decade. One example is the manufacture of methyl acetate by the Eastman Chemical Company [1].In their case, a single reactive distillation column has replaced the traditional flow sheet consisting of eleven major unit operations along with other equipment such as heat exchangers, pumps and controllers. The result had been a fivefold reduction in capital investment and energy consumption when compared to methyl acetate production using conventional designs[1].

Improved conversion and selectivity, reduced catalyst requirement, avoidance of azeotropes, reduced by-product formation and heat integration have been identified as the benefits of reactive distillation [5].In reactive distillation, higher conversions are obtained for equilibrium limited reactions because of the shifting of the equilibrium to the right [6].This is exemplified by the production of methyl acetate, methyl-tert butyl ether(MTBE) and tert-amyl ether [4].In some applications, chemical reaction has the beneficial effect of "reacting away" some of the azeotropes in the mixture and greatly simplifying the phase equilibrium behaviour. This happens in the MTBE synthesis processes. Improved selectivity is obtained by removal of products from the reaction zone and thereby preventing them from undergoing further reactions producing by-products[7] [8].Such benefits are obtained for example in the production of propylene oxide from propylene chlorohydrins, alkylation of benzene to produce cumene and alkylation of butane to produce isooctane.

K.K.C.W. Kandanapitiya, B.Sc. Eng. (Moratuwa), Research Student, Department of Chemical and Process

Engineering, University of Moratuwa, Sri Lanka.

Eng. (Dr.) M. Y. Gunasekera, B.Sc. Eng.(Hons)

(Moratuwa), M. Eng.(Moratuwa), PhD. (UK), MIE (Sri Lanka), Senior Lecturer, Department of Chemical \& Process Engineering, University of Moratuwa, Sri Lanka. 
Benefits of heat integration are obtained because of the heat generated in the chemical reactions is used for vaporization [8].This is particularly advantageous in situations involving high heats of reaction such as in the hydration of ethylene oxide to ethylene glycol. Hot spot formation is therefore prevented.

Esterification reactions of n-butanol, isobutyl alcohol, amyl alcohol and hexanol with acetic acid are common reactive systems which use reactive distillation. These alcohols are sparingly soluble in water and the ester is almost insoluble.

Butyl acetate is an important chemical which is used as a versatile solvent in various applications. It is commonly synthesized by esterification of n-butanol with acetic acid in the presence of an acid catalyst. A homogenous catalyst is used in this reaction. Difficulty in separating catalyst from the product stream, corrosion and disposal problems are likely to occur in homogenous catalyzed processes [9].

Amyl acetate is another important solvent ester that may be synthesized using reactive distillation. It is four times more efficient to use reactive distillation than reactor and column separately in terms of the total annual cost. Methyl isopropyl acetate is an important solvent used as a component in paints and adhesives because of its unique ability to dissolve both polar and non-polar compounds. The reaction is carried out in a reactive distillation column with acetic acid and 2methyl propanol in the presence of ion exchange resins. Methyl acetate is used as an intermediate in the manufacture of a variety of polyesters such as photographic film base, cellulose acetate, tenite cellulosic plastics and estron acetate[9].

The optimal performance of reactive distillation processes depends strongly on the reliability of the process design, proper selection of column internals, feed locations, choice of the catalyst, as well as on the extent of understanding of the process behaviour that is considerably more complex than that of conventional reactor separator sequences. The introduction of the separation function within the reaction zone leads to complex interactions between vapour liquid equilibrium, vapour liquid mass transfer, intracatalyst diffusion in heterogeneously catalysed processes and chemical kinetics. Such interactions have shown to lead to the phenomenon of multiple steady state and complex dynamics, which have been verified in experimental laboratory and pilot plant units. Experimental work involved in determining important data that are required by reactive distillation design engineers is expensive and time consuming. Therefore, reliable and accurate modelling and simulation procedures are required to generate such data without much cost and time. This work presents mathematical modelling and the simulation of batch reactive distillation to generate key information needed by reactive distillation design engineers.

\subsection{Types of Reactive Distillation Models}

For modelling reactive distillation columns, two distinctly different approaches are available in the literature:

(1) Equilibrium (EQ) stage model: In this model the vapour and liquid phases are assumed to be in thermodynamic equilibrium.

(2) Non equilibrium (NEQ)stage model: In this model finite mass transfer rates across the vapour liquid interface are assumed.

Assumptions used in the development of these models are as follows:

- Each stage is perfectly mixed i.e. liquid composition in each stage is homogeneous and equal to the composition of liquid leaving the stage.

- Entrainment of liquid drops in vapour and occlusion of vapour bubbles in liquid are negligible.

- Vapour molar holdup and vapour phase chemical reactions are negligible.

The principal assumption of the equilibrium stage model is that the vapour and the liquid streams that leave the stage are in thermodynamic equilibrium. In most distillation columns the residence time is too short to reach total equilibrium. For this reason, efficiencies have been introduced into the model, for example Murphree efficiency and vaporization efficiency to account for the non ideal behaviour. The material balance (M), equilibrium relationship (E), summation of all substances (S), and enthalpy balance (H)equations (acronym: MESHequations) are used in simulating conventional distillation columns [10].

The vapour from the stage below and liquid from the stage above are brought into 
contact with each other on the stage, together with any fresh or recycle feeds. The vapour and liquid streams leaving the stage are assumed to be in equilibrium with each other. The MESH equations are used in modelling these equilibrium stages. This type of modelling has been used by Estrada and Bogle in their work on exploring the interaction between flows and composition in reactive distillation[11].

The NEQ model, predicts the simulation more accurately than the equilibrium model (EQ) as this model needs accurate prediction of tray efficiency[12]. In non equilibrium models mass transfer is modelled as in multi component systems using Maxwell Stefan theory[8]. At the vapour liquid interface, phase equilibrium is assumed. The inter phase energy transfer rates are assumed to be equal in both phases having conductive and convective contributions. However the conductive contributions are ignored in some modelling studies. The applications of NEQ model can be found in mass transfer studies done by Krishna and Wesselingh and in multicomponent mass transfer work done by Taylor and Krishna[13],[14].

\section{Model Equations}

In order to develop model equations, a batch reactor with a condenser reflux drum is considered as shown in Figure 1.

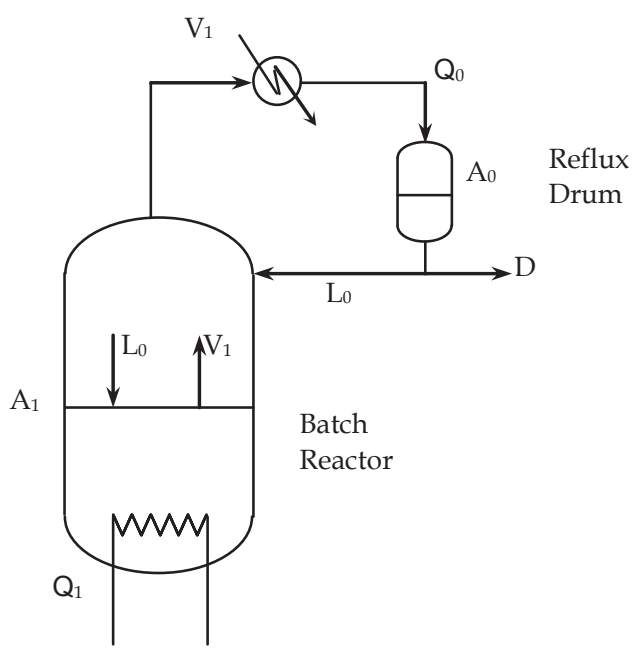

Figure 1 - Single Stage Batch Reactive Distillation Process

The predictive process design requires mass transfer, heat transfer, reaction kinetics and summation equations. Batch reactive distillation unit containing $\mathrm{A}_{1}$ molar holdup constitutes $x$ mole fraction of the $\mathrm{i}^{\text {th }}$ component. Reactor heat duty is $\mathrm{Q}_{1}(\mathrm{~J} / \mathrm{s})$ and vapour, $\mathrm{V}_{1}$ leaving the distillation unit has $y$ vapour composition. Vapour enters the condenser with $\mathrm{Q}_{0}$ heat duty and produces $\mathrm{L}_{0}$ reflux and $\mathrm{D}$ distillate. Chemical reactions are assumed to occur only in the liquid phase and vapour phase holdup is neglected. The homogeneous liquid phase is considered to be in equilibrium with the vapour. The heat of reaction is also considered in developing enthalpy balance equations. Heat lost into the environment is neglected. The system is assumed to be operating under atmospheric pressure and the vapour phase is assumed to be ideal. In bubble point calculations, the activity coefficient of the liquid phase is used. The liquid and vapour entrainment are assumed to be negligible in developing model equations. The modelling of reactive distillation requires $\mathrm{MESH}$ equations.

\subsection{Total mole balance for condenser-} reflux drum

In the overall mole balance over condenser reflux drum, the rate of molar flow into the condenser reflux drum is equated to the rate of flow of moles out, rate of moles reacted within and the rate of accumulation of moles in the condenser reflux drum.

$$
\begin{aligned}
& V_{1}=L_{0}+D-\sum_{i=1}^{c} \frac{d N_{0, i}}{d t}+\frac{d A_{0}}{d t} \\
& \sum_{i=1}^{c} \frac{d N_{0, i}}{d t}=A_{0} \sum_{i=1}^{c} R_{0, i}
\end{aligned}
$$

By substituting the moles consumed in the reaction using the rate of reaction equation (2) and by rearranging results, the following model equation (3) is derived.

$$
\frac{d A}{d t}=V_{1}-L_{0}-D+A \sum_{i=1}^{c} R_{0, i}
$$

\subsection{Component wise mole balance for condenser-reflux drum}

The rate of component moles flowing into the condenser reflux drum is equated to the rate of component moles flowing out, the rate of component moles lost due to chemical reaction within the system and the rate of accumulation of component moles.

$$
V_{1} y_{i}=\left(D+L_{0}\right) x_{0, i}-\frac{d N_{0, i}}{d t}+\frac{d A_{0} x_{0, i}}{d t}
$$

By substituting from equation (3) and rearranging, 


$$
\frac{d x_{0, i}}{d t}=\frac{V_{1}}{A_{0}}\left(y_{1, i}-x_{0, i}\right)+R_{0, i}-x_{0, i} \sum_{i=1}^{c} R_{0, i}
$$

\subsection{Overall Enthalpy Balance around Condenser Reflux Drum}

For the enthalpy balance, the rate of heat flowing into the condenser reflux drum is equated to the rate of heat flowing out, the rate of disappearance of heat by reaction within the condenser reflux drum and the rate of accumulation of heat. Considering the rate of heat flowing out of the condenser reflux drum as $\mathrm{Q}_{0}$ :

$$
H_{V, 1} V_{1}=H_{L, 0}\left(L_{0}+D\right)+\left(-A_{0} R_{0} \Delta H_{r}\right)+Q_{0}+A_{0} \frac{d H_{L, 0}}{d t}+H_{L, 0} \frac{d A_{0}}{d t}
$$

By substituting equation (3):

$$
\frac{d H_{L, 0}}{d t}=\frac{V_{1}}{A_{0}}\left(H_{V, 1}-H_{L, 0}\right)+R_{0} \Delta H_{r}-\frac{Q_{0}}{A_{0}}-H_{L, 0} \sum_{i=1}^{c} R_{0, i}
$$

\subsection{Total mole balance for reactor batch}

Similar to the mole balance done for the condenser drum, by applying mole balance for the reactor batch:

$$
L_{0}=V_{1}-\sum_{i=1}^{c} \frac{d N_{1, i}}{d t}+\frac{d A_{1}}{d t}
$$

The molar hold up in the batch reactor is $A_{1}$. By substituting from the rate of reaction equation (2) and rearranging,

$$
\frac{d A}{d t}=L_{0}-V_{1}+A \sum_{i=1}^{c} R_{1, i}
$$

\subsection{Component wise Mole Balance for Reactor Batch}

By applying mole balance for the reactor batch for one componenti,

$$
L_{0} X_{0, i}=V_{1} y_{1, i}-\frac{d N_{1, i}}{d t}+\frac{d A_{1} X_{1, i}}{d t}
$$

By substituting from equation (6)

$$
\frac{d x_{1, i}}{d t}=\frac{L_{0}}{A}\left(x_{0, i}-x_{1, i}\right)+\frac{V_{1}}{A}\left(x_{1, i}-y_{1, i}\right)+\left(R_{1, i}-x_{1, i} \sum_{i=1}^{c} R_{1, i}\right)
$$

\subsection{Overall Enthalpy Balance around}

\section{Reactor Batch}

By applying the enthalpy balance for the reactor batch:

$$
\begin{gathered}
\frac{d H_{L, 1}}{d t}=\frac{Q_{1}}{A}-\frac{L_{0}}{A}\left(H_{L, 1}-H_{L, 0}\right)-\frac{V_{1}}{A}\left(H_{V, 1}-H_{L, 1}\right) \\
+R_{1} \Delta H_{r}-H_{L, 1} \sum_{i=1}^{c} R_{1, i}
\end{gathered}
$$

\subsection{Other Model Equations}

\section{Equilibrium Relationship}

The equilibrium relationship is obtained by the modified Raoult's law which is valid for low to moderate pressures [15]. The modified Raoult'slaw for low to moderate pressure is given by equation (9):

$$
y_{i} P=x_{i} \gamma_{i} P_{i}^{\text {sat }}
$$

The individual values of $y_{i}$ and $x_{i}$ should satisfy the summation.

$$
\sum_{i=1}^{c} x_{i}=1 \quad \sum_{i=1}^{c} y_{i}=1
$$

\section{Enthalpy Relationship}

Liquid and vapour enthalpies are calculated using the following equations [9] [15].

$$
\begin{aligned}
H^{L} & =\sum_{i=1}^{c} x_{i} c_{p, i}^{L} T \\
H^{V} & =\sum_{i=1}^{c} y_{i}\left(h_{i}{ }^{L}+h_{f g, i}\right)
\end{aligned}
$$

\subsection{Degrees of Freedom}

The degree of freedom is the number of variables that must be specified in order to define the process completely. This can be found by subtracting the number of independent equations from the number of variables. The Table 1 shows the number of independent equations.

Table 1- Number of Independent Equations

\begin{tabular}{|c|c|}
\hline $\begin{array}{c}\text { Equation } \\
\text { Number }\end{array}$ & $\begin{array}{c}\text { Number of independent } \\
\text { equations }\end{array}$ \\
\hline 1 & 1 \\
\hline 2 & 4 \\
\hline 3 & 1 \\
\hline 4 & 1 \\
\hline 5 & 4 \\
\hline 6 & 1 \\
\hline 7 & 4 \\
\hline 8 & 2 \\
\hline 9 & 1 \\
\hline
\end{tabular}

According to Table 1, the total number of independent equations is 19. The variables in modelling equations are as follows:

$$
\begin{array}{lccccc}
A_{0} & x_{0,1} & x_{0,2} & x_{0,3} & x_{0,4} \\
H_{L, 0} & V_{1} & L_{0} & D & \\
A & x_{1,1} & x_{1,2} & x_{1,3} & x_{1,4} \\
\multicolumn{7}{c}{H_{L, 1}} & Q_{0} & Q_{1} & P \\
y_{1,1} & y_{1,2} & y_{1,3} & y_{1,4} &
\end{array}
$$

The degrees of freedom $(\mathrm{F})$ can be equated to the total number of variablesminus the total number of independent equations. In this study this is equal to $(22-19)=3$. 


\subsection{Reaction Kinetics}

The reaction kinetics will depend on the type of reaction taking place. For example, acetic acid reacting with ethanol in the presence of a catalyst will give ethyl acetate and water. This is an exothermic reversible reaction and can be written as:

$\mathrm{CH}_{3} \mathrm{COOH}(\mathrm{AA})+\mathrm{C}_{2} \mathrm{H}_{5} \mathrm{OH}(\mathrm{E}) \stackrel{\text { catalyst }}{\longrightarrow} \mathrm{CH}_{3} \mathrm{COOC}_{2} \mathrm{H}_{5}(\mathrm{EAC})+\mathrm{H}_{2} \mathrm{O}(\mathrm{W})$

\section{Homogeneous Reaction Kinetics}

The reaction rate can be written as follows for homogeneous catalyst sulphuric acid,

$$
r=K_{f} C_{A A} C_{E}-K_{r} C_{E A c} C_{W}
$$

Where forward and reversible reaction rate constant values are [16],

$$
\begin{aligned}
& K_{f}=4.76 \times 10^{-4} \text { litre } / \text { gmol.min } \\
& K_{r}=1.63 \times 10^{-4} \text { litre } / \text { gmol.min }
\end{aligned}
$$

\section{Simulation Method}

The differential equations were converted to algebraic equations using Euler method. In order to calculate vapour phase composition, the bubble point calculation method was used[10]. Two separate computer programmes were written using the MATLAB environment. Figure 2 illustrates the modelling and simulation of this reactive distillation process.

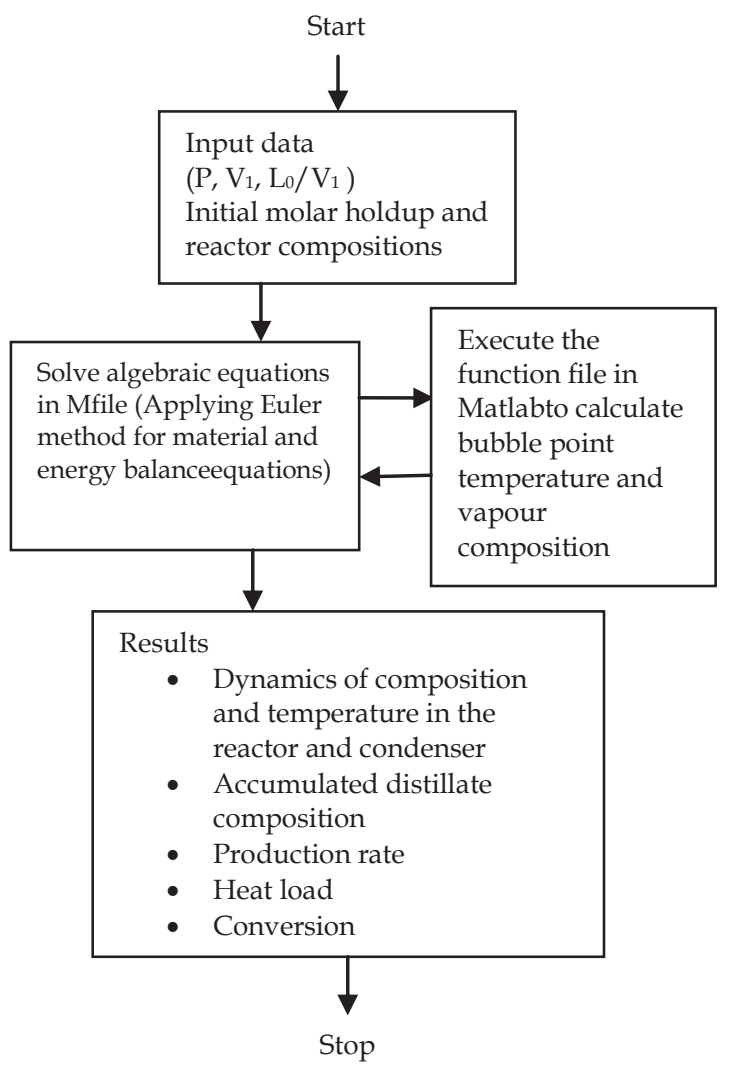

Figure 2-Flow Chart of the Simulation Method
An $\mathrm{M}$ file for solving algebraic equations with reaction kinetics and a function file for calculating the bubble point were developed. In the simulation both files were executed simultaneously. The dynamics of the reactor and condenser were observed until ethanol composition fell to $5 \%$ in the reactor batch. Simulation results were obtained for $\mathrm{L}_{0} / \mathrm{V}_{1}$ ratio values $0.85,0.9,0.95$ and0.975. The value of $\mathrm{V}_{1}$ was assumed to be 90 moles/hr while $\mathrm{L}_{0}$ and $\mathrm{D}$ values were calculated for this constant condenser hold up.

\section{Simulation Results}

The variation of the species compositions in the reactor batch and the condenser reflux drum with time are shown in Figure 3 and Figure 4 respectively. In the reactor batch, as the reaction proceeds, initially acetic acid and ethanol reactants composition decreases while water and ethyl acetate composition increases. However after some time although ethanol mole fraction keeps on reducing, acetic acid concentration rises due to the increase in boiling point of the mixture.

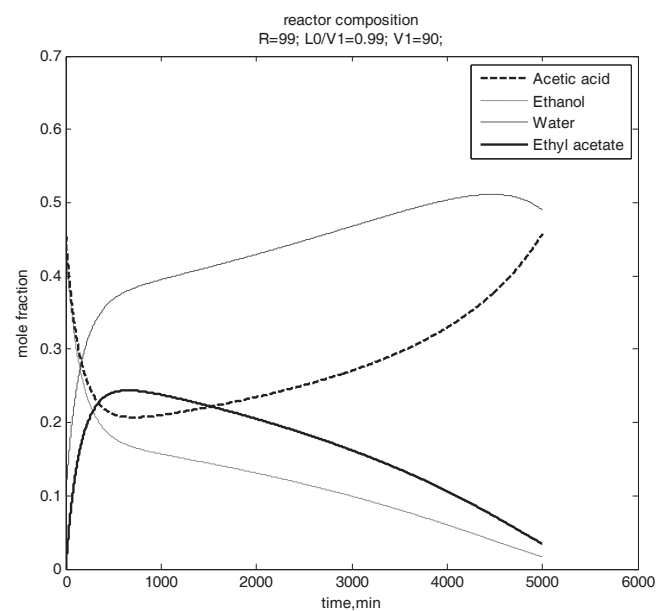

Figure 3 -Reactor Composition Variation at Reflux 99 


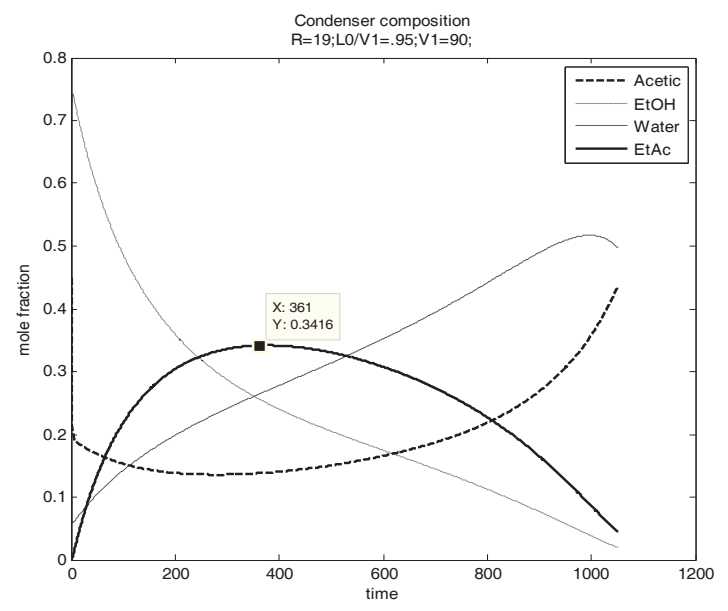

Figure 4 -Dynamics of Condenser Composition at Reflux Ratio 19

Condenser composition results show a decrease in acetic acid concentration initially followed by an increase. Ethanol mole fraction decreases throughout the batch time. Ethyl acetate increases as the reactive distillation takes place achieving a maximum and starts to decrease thereafter. Similar composition variations are observed for other reflux ratios too.

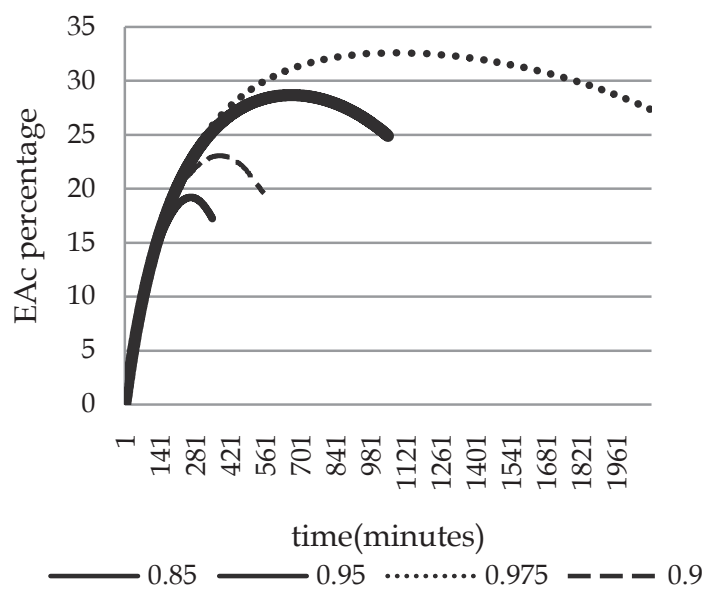

Figure 5 - Dynamics of Accumulated Distillate at Different $\mathrm{L}_{0} / \mathrm{V}_{1}$ Rratios

In Figure 5, Ethyl Acetate mole fraction in the accumulated distillate increases with time and achieves a maximum value. Similar results have been observed by Patel et al in their reactive distillation modelling study [10]. The maximum value of ethyl acetate declines with the decrease in the reflux ratio. The ethyl acetate percentage gets its maximum value with less time with the decrease in the reflux ratio.
Table 2 - Summary of the simulation results

\begin{tabular}{|l|l|l|l|l|l|}
\hline $\begin{array}{c}\mathrm{L}_{0} / \mathrm{V}_{1} \\
\text { ratio }\end{array}$ & $\begin{array}{c}\mathrm{A}_{\mathrm{p}} \\
\text { EAc } \\
(\mathrm{moles})\end{array}$ & $\begin{array}{c}\mathrm{Tb} \\
(\mathrm{hrs})\end{array}$ & $\begin{array}{c}\text { Produ } \\
\text { ction } \\
\text { rate }\end{array}$ & $\begin{array}{c}\text { EAc } \\
\text { Mole } \\
\%\end{array}$ & $\begin{array}{c}\text { Maximum } \\
\text { Purity of } \\
\text { EAc in } \\
\text { condenser }\end{array}$ \\
\hline 0.85 & 816 & 6.15 & 132.82 & 16.38 & 0.2495 \\
\hline 0.9 & 976 & 9.15 & 106.68 & 19.76 & 0.2901 \\
\hline 0.95 & 1176 & 17.48 & 67.30 & 24.93 & 0.3449 \\
\hline 0.975 & 1290 & 34.98 & 36.89 & 27.33 & 0.3752 \\
\hline
\end{tabular}

Although the increase in reflux ratio has resulted in an increase in ethyl acetate moles in the accumulated distillate, the batch time required is high. Therefore in order to produce ethyl acetate above $19 \%$ the most suitable $\mathrm{L}_{0} / \mathrm{V}_{1}$ value from the results of this study is 0.9 where the reflux ratio is 9. For this operating condition the mole percentage of the accumulated distillate is $19.76 \%$ which is achieved within a batch time of $9.15 \mathrm{hrs}$.It is recognized that for practical applications this batch time may be considered as too long. Values of $\mathrm{L}_{0} / \mathrm{V}_{1}$ below 0.9 give lower ethyl acetate percentages and ratios above 0.9 need higher batch times. The reactor heat load results show an increase from $0.92 \times 10^{6} \mathrm{~kJ}$ to $5.54 \times 10^{6} \mathrm{~kJ}$ when $\mathrm{L}_{0} / \mathrm{V}_{1}$ value increases from 0.85 to 0.975.Although in this work the operating pressure is taken as constant at atmospheric pressure, in industrial scale applications there could be variations in this pressure.

\section{Conclusions}

Material balance equations, energy balance equations, summation equations and equilibrium relationships are required for reactor batch and condenser separately. There are 19 independent equations and 22 variables in the model for a condenser and a batch reactor. Three variables should be specified to define the process completely. This model can be used for other equilibrium reactions by adjusting reaction kinetics and vapour equilibrium data. Under the reaction conditions studied in this work, the most suitable reflux ratio that will produce ethyl acetate above about $19 \%$ was found to be 9 .

\section{Nomenclature}

A - Molar hold up (moles)

$A_{p}$ - Ethyl acetate moles in accumulated distillate

c - Number of components

$\mathrm{D}$-Distillate flow rate $(\mathrm{mol} / \mathrm{s})$

$\mathrm{H}_{\mathrm{L}}$ - Liquid enthalpy $(\mathrm{J} / \mathrm{mol})$

$\mathrm{H}_{\mathrm{v}}$ - Vapour enthalpy $(\mathrm{J} / \mathrm{mol})$

$\mathrm{L}_{0}$ - Liquid flow rate (mol/s)

$\mathrm{N}_{\mathrm{i}}$ - Moles of $\mathrm{i}^{\text {th }}$ component formed 
$\mathrm{P}$ - Pressure $\left(\mathrm{N} / \mathrm{m}^{2}\right)$

Psat $_{i}$ - Saturation temperature of component $\mathrm{i}$ $\left(\mathrm{N} / \mathrm{m}^{2}\right)$

$\mathrm{Q}_{0}$-Heat duty on condenser-reflux $\operatorname{drum}(\mathrm{J} / \mathrm{s})$

$\mathrm{Q}_{1}$ - Heatduty on reboiler $(\mathrm{J} / \mathrm{s})$

$\mathrm{R}$ - Rate of reaction $\left(\mathrm{mol} / \mathrm{m}^{3} . \mathrm{s}\right)$

$\mathrm{R}_{1, \mathrm{i}}$ - Rate of reaction of the $\mathrm{i}^{\text {th }}$ component in the reactor batch

$\mathrm{Tb}$ - Batch time

$\mathrm{V}$ - Vapour flow rate $(\mathrm{mol} / \mathrm{s})$

$x_{i}$-Molefraction of the $i^{\text {th }}$ component in the liquid phase

$y_{i}$.Molefraction of the $i^{\text {th }}$ component in the vapor phase

$\Delta \mathrm{H}_{\mathrm{r}}$-Heat of reaction $(\mathrm{J} / \mathrm{mol})$

$\gamma$ - Activity coefficient

Subscripts:

i -Component number 1 to $\mathrm{c}$

0 - Condenser reflux drum

1 - Reactor batch

V - Vapour

L - Liquid

\section{Acknowledgment}

This research project was supported by the University of Moratuwa Senate Research Grant Number SRC/LT/2012/10.

\section{References}

1. Huss, R. S., Chen, F., Malone, M. F., Doherty, M. F., "Reactive Distillation for Methyl Acetate Production", Computers and Chemical Engineering, Vol.27, 2003, pp.1855-1866.

2. Almeida-Rivera, C. P., Swinkels, P. L. J., Grievink, J., "Designing Reactive Distillation Processes: Present and Future", Computers and Chemical Engineering, Vol. 28, 2004, pp.1997-2020.

3. Harmsen, G. J., "Reactive Distillation: The FrontRunner of Industrial Process Intensification, A full Review of Commercial Applications, Research, Scale-up, Design and Operation", Chemical Engineering and Processing,Vol.46, 2007, pp.774-780.

4. Rameshwar, S. H., Bhate, N. V., Mahajan, Y. S., Mahajani, S. M., "Industrial Applications of Reactive Distillation: Recent Trends", International Journal of Chemical Reactor Engineering, Vol. 2,2004

5. Kenig, E.Y., Bader H., "Investigation of Ethyl Acetate Reactive Distillation Process", Chemical Engineering Science,Vol.56, 2001, pp. 6185-6193.

6. Bhatia, S., Mohamed, A. R., Ahmad, A. L., Chin, S. Y., "Production of Isopropyl Palmitate in a Catalytic Distillation Column: Comparison between Experimental and Simulation Studies", Computers and Chemical Engineering,Vol.31, 2007,pp. 1187-1198.

7. Murat, M. N., Mohamed, A. R., Bhatia S., "Modelling of a Reactive Distillation Column. Methyl Tertiary butyl ether (MTBE) Simulation studies", ITUM Engineering Journal,Vol.4,No.2,2003.

8. Taylor, R., Krishna, R., “Modelling Reactive Distillation Review", Chemical Engineering Science, Vol.55, 2000, pp.5183-5229.

9. Hiwale, R. S., Bhate, N. V., Mahajan, Y. S., \& Mahajani, S. M., "Industrial Applications of Reactive Distillation: Recent Trends", International Journal of Chemical Reactor Engineering, Vol.2, 2004.

10. Patel, R., Singh, K., Pareek, V. \& Tade, M. O, "Dynamic Simulation of Reactive Batch Distillation Column for Ethyl Acetate Synthesis", Chemical Product and Process Modelling, Vol. 2 No.2, article 5, 2007.

11. EstradaVillagranna, A. D. \& Bogle, I. D. L., "Exploring the Interaction between Flows and Composition in Reactive Distillation", Computers and Chemical Engineering Supplement,S339S342,1999.

12. Lee, J. H., Dudukovic, M. P., "Dynamic Simulation of a Reactive Distillation Tray Column using a Rate -Based Model", Paper presented at AIChE National meeting, Dallas, 1999.

13. Krishna, R. \& Wesselingh, J. A., "The MaxwellStefan Approach to Mass Transfer", Chemical Engineering Science,Vol.52,1997, pp.861-911.

14. Taylor, R., \& Krishna, R., Multicomponent Mass Transfer, New York:Wiley, 1993.

15. Smith, J. M., VanNess, H. C., Abbot, M. M., Introduction to Chemical Engineering Thermodynamics, New York:TheMcGraw Hill companies Inc., 1996.

16. Mujtaba, I. M, and Macchietto, S., "Efficient Optimization of Batch Distillation with Chemical Reaction using Polynomial Curve Fitting Techniques", Industrial \& Engineering Chemistry Research, Vo.36, No.6,1997,pp.2287-2295. 